\section{Inheritance Analysis and Quantitative Trait Loci Detection of Head Splitting Resistance in Cabbage (Brassica oleracea L. var. capitata)}

\author{
Yanbin Su \\ Institute of Vegetables and Flowers, Chinese Academy of Agricultural Sciences, \\ Key Laboratory of Biology and Genetic Improvement of Horticultural Crops, \\ Ministry of Agriculture, Beijing 100081, People's Republic of China; China \\ Agricultural University, Beijing 100194, People's Republic of China
}

Yumei Liu ${ }^{1}$

Institute of Vegetables and Flowers, Chinese Academy of Agricultural Sciences, Key Laboratory of Biology and Genetic Improvement of Horticultural Crops, Ministry of Agriculture, Beijing 100081, People's Republic of China

Huolin Shen and Xingguo Xiao

China Agricultural University, Beijing 100194, People's Republic of China

Zhansheng Li, Zhiyuan Fang, Limei Yang, Mu Zhuang, and Yangyong Zhang

Institute of Vegetables and Flowers, Chinese Academy of Agricultural Sciences, Key Laboratory of Biology and Genetic Improvement of Horticultural Crops, Ministry of Agriculture, Beijing 100081, People's Republic of China

Additional index words. cabbage, resistance to head splitting, major gene and polygene inheritance model, genetic analysis, QTL detection

\begin{abstract}
Head splitting resistance (HSR) in cabbage is an important trait closely related to appearance, yield, storability, and mechanical harvestability. In this study, a doubled haploid (DH) population derived from a cross between head splitting-susceptible inbred cabbage line 79-156 and resistant line 96-100 was used to analyze inheritance and detect quantitative trait loci (QTLs) for HSR during 2011-12 in Beijing, China. The analysis was performed using a mixed major gene/polygene inheritance method and QTL mapping. This approach, which uncovered no cytoplasmic effect, indicated that HSR can be attributed to additive-epistatic effects of three major gene pairs combined with those of polygenes. Major gene and polygene heritabilities were estimated to be $\mathbf{8 8 . 0 3 \%}$ to $88.22 \%$ and $5.65 \%$ to $7.60 \%$, respectively. Using the DH population, a genetic map was constructed with simple sequence repeat (SSR) markers anchored on nine linkage groups spanning $906.62 \mathrm{cM}$. Eight QTLs for HSR were located on chromosomes C4, C5, C7, and C9 based on 2 years of phenotypic data using both multiple-QTL mapping and inclusive composite interval mapping. The identified QTLs collectively explained $37.6 \%$ to $46.7 \%$ of phenotypic variation. Three or four major QTLs (Hsr 4.2, 7.2, 9.3, and/or 9.1) showing a relatively larger effect were robustly detected in different years or with different mapping methods. The HSR trait was shown to have a complex genetic basis. Results from QTL mapping and classical genetic analysis were consistent. Our results provide a foundation for further research on HSR genetic regulation and molecular markerassisted selection (MAS) for HSR in cabbage.
\end{abstract}

Received for publication 2 Feb. 2015. Accepted for publication 9 Apr. 2015.

This work was funded by the National High Technology Research and Development Program (863 Program, 2012AA100104, 2012AA100105), Chinese National Key Technology R\&D Program (2013BAD01B04), the Earmarked Fund for Modern Agro-industry Technology Research System (CARS-25-A), and Key Laboratory of Biology and Genetic Improvement of Horticultural Crops, Ministry of Agriculture, People's Republic of China.

${ }^{1}$ To whom reprint requests should be addressed; e-mail liuyumei@caas.cn. susceptibility to head splitting hinders the prolongation of harvest time and thus the ability of growers to select harvest times for optimal selling price. Head splitting resistance is thus a very desirable property in cabbage (Holt and Schoorl, 1983). Previous studies (Liu et al., 2009; Zeng et al., 2009) about this trait mainly concentrated on cultivating conditions, physiological, cytological characters, and types of the head. It is proved that many factors, such as irrigation, fertilizer, planting density, endogenous hormones content, leaf surface microconfiguration, and tissue character could affect the cracking head. To alleviate late-stage head splitting, farmers generally reduce irrigation times during cultivation. Such practices affect normal cabbage head growth, however, and cannot completely prevent head splitting. Under water-sufficient conditions, head splitting in cabbage is mainly caused by genetic factors (Qin et al., 1994). Improvement of HSR in newly developed varieties has therefore become a priority in cabbage breeding programs. The complex genetic nature of the HSR trait has only been explored in a few studies. After performing a cross between early- and late-splitting cabbage lines and obtaining their $F_{1}, F_{2}$, and backcross progenies, Chiang (1972) concluded that HSR is controlled by at least three pairs of genes within an average of six generations. Gene action was found to be mostly additive. Partial dominance for early splitting was detected, and narrow sense heritability was estimated as $47 \%$. Zhuang et al. (2009) further analyzed combining ability and heritability according to the Griffing IV method. Using 15 cross combinations involving six backbone parents, they revealed that HSR is controlled by both additive and nonadditive effects. Additive effects were found to be the most important, with the percentage contribution of additive effects increasing with prolongation of field duration. These classical genetic methods revealed that HSR is complex and controlled by many genes, and also estimated the total gene effect. Nevertheless, major gene effects and polygene effects were not clearly distinguished and the gene relationships were not identified.

Major gene/polygene genetic segregation analysis and QTL mapping are the main approaches used to clarify the genetic basis of quantitative traits (Gai et al., 2007; Zhang et al., 2003). These methods have been successfully applied to uncover inheritance patterns and QTLs of important traits in many crops, vegetables, and flowers (Anbessa et al., 2006; Cheng et al., 2011; Hao et al., 2008; Liang et al., 2014; Wang et al., 2012b; Zhang et al., 2010, 2013).

For QTL mapping, the use of DH populations is a powerful tool. Because each line is homozygous, they can be replicated between test sites, and trialed over multiple years. So the standard error of QTL genotype means is thus decreased, thereby allowing a better estimate of trait heritability and increasing QTL detection ability (Pink et al., 
2008; Simon et al., 2008). At the same time, multiple mapping methods for detecting QTLs are needed to effectively identify and verify important QTLs (Su et al., 2010; Xing et al., 2012).

Recent progress in genetic mapping and molecular marker development in B. oleracea have laid an important foundation for genetic studies and QTL analysis of important B. oleracea traits (Brown et al., 2014; Gao et al., 2007; Walley et al., 2012; Wang et al., 2012a). QTL mapping studies in cabbage have mainly concentrated on plant size (Lan and Paterson, 2001), flowering time (Okazaki et al., 2007), and disease resistance (Kifuji et al., 2012; Nagaoka et al., 2010; Mei et al., 2013). No QTL mapping studies associated with cabbage HSR have been reported.

To thoroughly dissect the genetic architecture of HSR in cabbage, we first developed an intracrop 'immortal' DH mapping population derived from a cabbage $\mathrm{x}$ cabbage cross and used it in a segregation analysis over multiple generations $\left(\mathrm{P}_{1}, \mathrm{P}_{2}\right.$, and $\left.\mathrm{DHs}\right)$ to explain HSR inheritance. We then constructed a framework linkage map based on this DH population with SSR markers. Finally, we located the first-known cabbage QTLs for HSR on the generated linkage map and analyzed QTL stability across years with different mapping programs.

\section{Materials and Methods}

Plant materials. Two inbred cabbage lines (Fig. 1), 96-100 and 79-156, were used as parents to develop a $\mathrm{DH}$ population. The male parental line, 96-100 $\left(\mathrm{P}_{2}\right.$, about $50 \mathrm{~d}$ form transplantation to maturity in autumn), is resistant to head splitting and was selfdeveloped from germplasm of Indian origin introduced by the Bejo Sheetal Company; the female parental line, 79-156 $\left(\mathrm{P}_{1}\right.$, about $50 \mathrm{~d}$ form transplantation to maturity in autumn), is susceptible to head splitting and selfdeveloped from a germplasm introduced from Denmark. Both of the parents are early maturing inbred lines and were provided by the Cabbage and Broccoli Laboratory, Institute of Vegetables and Flowers, Chinese Academy of Agricultural Sciences (CAAS). The $\mathrm{DH}$ population was derived from the $\mathrm{F}_{1}$ (79-156 $\times 96-100)$ by microspore culture (Yuan et al., 2011, 2012) during 2009-12.

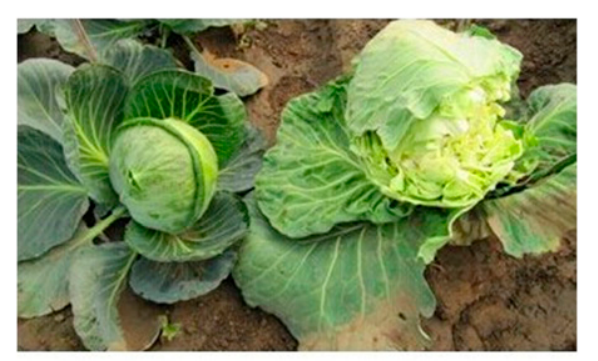

'96-100', ' $79-156$ '

Fig. 1. The difference between parents in headsplitting resistance trait.
Seeds were obtained from $157 \mathrm{DH}$ individuals in the summer of 2011 and from 181 individuals in 2012. All DH lines obtained in the 2 years were used for genetic segregation analysis. For linkage map construction and mapping, data from the first 157 lines were used.

Field experiments, resistance evaluation, and statistical analysis. Parents, $\mathrm{F}_{1}(79-156 \times$ 96-100), $\mathrm{RF}_{1}(96-100 \times 79-156)$, and $\mathrm{DH}$ lines were planted in the field at the experimental farm of the Institute of Vegetables and Flowers, CAAS (Changping, Beijing, China) in 2011 and 2012. Seeds of each generation were sown in a greenhouse in mid-July, and the resulting seedlings were transplanted into $10-\mathrm{cm}$ diameter plastic pots after 3 weeks. The plants were then transplanted into the field at $\approx 5$ weeks of age (19 Aug. 2011 and 22 Aug. 2012). Parental, $F_{1}$, and $\mathrm{RF}_{1}$ lines were planted in a randomized complete block design with three replicates. In each replicate, parents and $F_{1}$ lines were planted in three rows; each row comprised 16 plants, spaced $40 \mathrm{~cm}$ apart within a row and $50 \mathrm{~cm}$ between rows. For the DH population, a block in replication design was adopted with three replicates (Gai, 2000; Supplemental Table 1). Each replicate consisted of single rows of 16 plants. The experimental plots were surrounded by two additional rows planted to serve as a protective buffer. Irrigation and insecticide application were consistent with commercial production conditions. In each replicate, 15 plants at the same growth level of each parental, $F_{1}$, and $R_{1}$ line and 10 plants of each DH line were marked for phenotypic measurements.

Because of differences in maturation rates due to genotypic variation, maturation dates were recorded for each DH line. At maturity, the height and the circumference of each marked cabbage head at its widest point were measured with a flexible plastic ruler. The arc length and width of the largest split were also measured with a flexible plastic ruler $15 \mathrm{~d}$ after maturity. Splitting was assessed on a 6-point scale, assigned according to the number of split layers and the ratio of the split size to the entire surface area (calculated as S [\%] = $\mathrm{S}_{1} / \mathrm{S}_{2} \times 100 \%$, where $\mathrm{S}_{1}=$ arc length $\times$ width of the largest split and $S_{2}=$ height $\times$ half of the largest circumference of the head) (Fig. 2). Assigned splitting scores were as follows: $0=$ no split; $1=1$ split layer; $2=2$ split layers and $\mathrm{S}<50 ; 3=3-5$ split layers and $\mathrm{S}<50$, or 2 split layers and $S \geq 50 ; 4=6-10$ split layers and $\mathrm{S}<50$, or $3-5$ split layers and $\mathrm{S} \geq 50 ; 5=$ more than 10 split layers, or $6-10$ split layers and $S \geq 50$. The head splitting index was calculated as: $\sum$ (splitting score $\times$ number of plants with that score)/(total number of plants $\times$ highest possible splitting score $) \times$ $100 \%$. The data were analyzed with Excel 2003 and SAS 8.1 software.

Joint segregation analysis. To determine an appropriate genetic model for the HSR trait, the cabbage $\mathrm{DH}$ population dataset was analyzed by major gene/polygene mixed inheritance analysis (Gai, 2006; Gai et al., 2003). Joint segregation analysis was performed following Hao et al. (2008) and Zhang et al. (2010) under the basic assumptions described by those authors. To select the genetic model best explaining the quantitative trait variation, 38 genetic models of 7 different types were considered (Supplemental Table 2). Maximum likelihood estimates of component parameters in each genetic model were generated using the iterated expectation and conditional maximization algorithm (Zhang et al., 2003). The proportion, mean, and variance of each component distribution in the likelihood function were included in the estimates. Best-fit models were chosen according to the Akaike information criterion (AIC) (Akaike, 1977) and a suite of goodness-of-fit tests. Finally, genetic parameters of major genes and polygenes were estimated based on the least squares principle.

DNA extraction. Total DNA was isolated from expanding leaves of 3-week-old plants using the modified cetyltrimethylammonium bromide method (Saghai-Maroof et al., 1984). The genomic DNA samples were diluted to $100 \mathrm{ng} / \mu \mathrm{l}$ with Tris-EDTA ( $\mathrm{pH}$ 8.0 ) and stored at $-20{ }^{\circ} \mathrm{C}$ for use as polymerase chain reaction (PCR) templates. In addition, leaf tissue was lyophilized for use in future DNA extractions.

Genetic linkage map construction and QTL mapping. A set of 2,170 SSR markers developed from cabbage sequence scaffolds (Wang et al., 2012a) and 1,013 expressed sequence tag (EST)-SSR markers (Chen et al., 2010a) were used to scan for polymorphisms between the two parents. DNA amplification of SSR markers was carried out in $20-\mu \mathrm{l}$ volumes containing 1 unit of Taq polymerase, $0.1 \mu \mathrm{M}$ of each primer, $200 \mu \mathrm{M}$ dNTPs, $2 \mu \mathrm{l}$ of $10 \times$ buffer $\left(25 \mathrm{mM} \mathrm{Mg}^{2+}\right)$, and $100 \mathrm{ng}$ genomic DNA template. The PCR thermal profile was as follows: initial denaturation for 5 min at $94^{\circ} \mathrm{C}$, followed by 35 cycles of DNA denaturation for $30 \mathrm{~s}$ at $94{ }^{\circ} \mathrm{C}$, annealing for $30 \mathrm{~s}$ at $55^{\circ} \mathrm{C}$, and extension for $45 \mathrm{~s}$ at $72^{\circ} \mathrm{C}$, and a final extension for $7 \mathrm{~min}$ at $72{ }^{\circ} \mathrm{C}$. PCR amplifications were carried out in a GeneAmp PCR system 9700 (Applied Biosystems, Foster City, CA). The resulting products were subjected to $8 \%$ polyacrylamide gel electrophoresis at $160 \mathrm{~V}$ for $1.5 \mathrm{~h}$ followed by silver staining (Brant et al., 1991).

Framework map construction and QTL analysis. For map construction, the DH population was genotyped for all SSR markers that showed polymorphisms between the parental 79-156 and 96-100 lines. The genotyping data were coded as type "a" or " $b$ ", corresponding to parental lines 79-156 and 96-100, respectively, with ambiguous and missing data indicated by “-”. A linkage map was constructed using JoinMap 4.0 software (Van Ooijen, 2006). For map distance calculations, recombination frequencies were converted to centiMorgans (cM) using Kosambi's method, and linkage groups were assigned to chromosomes $\mathrm{C} 1-\mathrm{C} 9$ of $B$. oleracea based on markers in common with the reference ( $\mathrm{Lv}$ et al., 2014; Wang et al., 2012a). 
QTLs were estimated by multiple-QTL modeling (MQM) with MapQTL 4.0 (Van Ooijen et al., 2002) and by inclusive composite interval mapping (ICIM) using QTL IciMapping v3.0 software ( $\mathrm{Li}$ et al., 2007). In MQM, a 1,000-permutation run was first performed to estimate the significance threshold of the test statistic for a QTL based upon a 5\% experiment-wise error rate. Interval mapping at 1-cM intervals along the chromosomes was then used to scan for QTLs based on a logarithm of odds (LOD) threshold of 2.5. Markers closely linked to positions with the highest LOD score were taken as cofactors for MQM analysis. To select significant markers during the first step of ICIM stepwise regression, $P$ values for entering and removing variables were set respectively at 0.001 and 0.002 ; in the second step, a minimum LOD threshold of 2.5 was used to declare a QTL significant.

\section{Results}

Phenotypic assessment of parental, $F_{1}$, $R F_{1}$, and DH lines. Parents 79-156 and 96100 differed significantly with respect to HSR (Fig. 1; Table 1). Line 96-100 was resistant to head splitting, with a head splitting index of 9.33 and 9.36 in 2011 and 2012, respectively; in contrast, 79-156 was highly susceptible to head splitting, with corresponding head splitting index values of 86.87 and 85.32 . Head splitting indexes of $\mathrm{F}_{1}$ and $\mathrm{RF}_{1}$ were not significantly different from one another; the values were intermediate to those of the parents, indicating that there is no cytoplasmic effect on HSR inheritance.

Analysis of variance revealed significant differences $(P<0.01)$ in HSR among DHs in both 2011 and 2012 (Table 2), indicating the
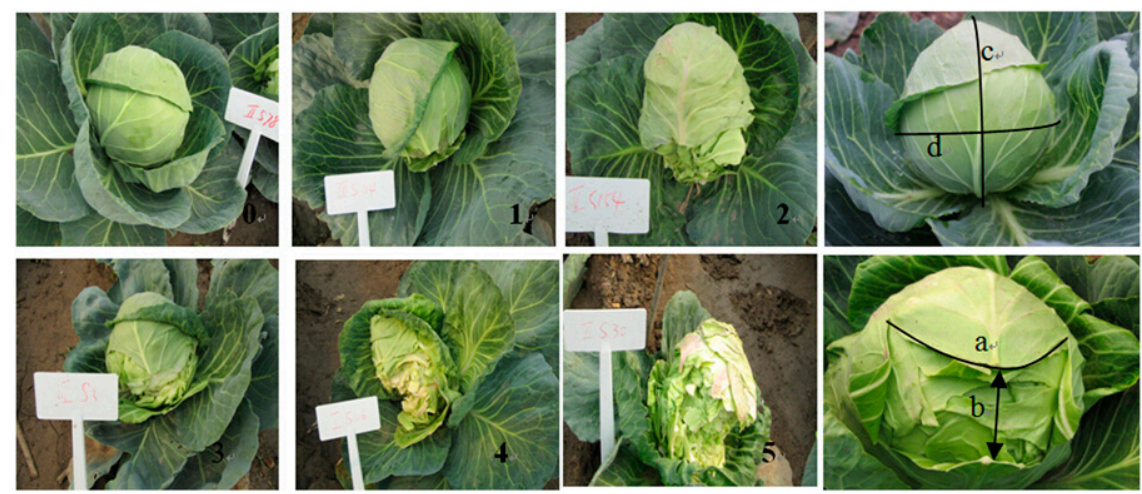

Fig. 2 . The grade $0-5$ of head-splitting resistance in DH population. $0=$ no split; $1=1$ split layer; $2=2$ split layers and $\mathrm{S}<50 ; 3=3-5$ split layers and $\mathrm{S}<50$, or 2 split layers and $\mathrm{S} \geq 50 ; 4=6-10$ split layers and $\mathrm{S}<50$, or $3-5$ split layers and $\mathrm{S} \geq 50 ; 5=$ more than 10 split layers, or 6-10 split layers and $\mathrm{S} \geq 50$. $\mathrm{a}=\operatorname{arc}$ length and $\mathrm{b}=$ width of the largest split; $\mathrm{c}=$ height of the head and $\mathrm{d}=$ the largest circumference of the head. $\mathrm{S}[\%]=\mathrm{S}_{1} / \mathrm{S}_{2} \times 100 \%$, where $\mathrm{S}_{1}=\mathrm{a} \times \mathrm{b}$ and $\mathrm{S}_{2}=\mathrm{c} \times 1 / 2 \mathrm{~d}$. the 15 parameters were observed to be significant in the 3 respective tests, while no statistic was significant under the G-0 model in 2011. The B-1-2 model could be eliminated in 2012 because five of the 15 parameters were found to be significant. Although only one parameter was significant under the other three models, the G-0 model was regarded as the best fit because it was associated with the lowest AIC score (Supplemental Table 3). We therefore deduced that HSR in cabbage can be described by a model corresponding to three pairs of additiveepistatic major genes plus additive-epistatic polygenes.

Maximum likelihood frequency values of eight component distributions were estimated under the G-0 model, with first- and secondorder genetic parameters then calculated from the results (Table 4) using the least squares method. The calculated parameters showed similar tendencies in both years; additive effects $(d)$ of the three major genes were estimated as 20.4, 8.59, and 15.89. All the additive effects were positive, indicating that the susceptible parental line 79-156 had important effects on total variability. The additive epistatic effect of the first two major genes, $i_{\mathrm{ab}}$, was 3.64 , while that between the first and third major genes, $i_{\text {ac }}$, was 10.94. The additive epistatic effect of the second and third major genes, $i_{\mathrm{bc}}$, was only -0.86 , while that among the three major genes, $i_{\mathrm{abc}}$, was -5.81 . Similar results were observed in 2012 . Heritabilities of major genes and polygenes in 2011 were 88.03 and $7.60 \%$, respectively, with corresponding values of 88.22 and $5.65 \%$ in 2012 . The heritability values of the major genes were much larger than those of the polygenes. These observations demonstrate that HSR is mainly controlled by major genes, and that selection for this trait should be carried out in early generations.

Linkage map construction and analysis. A preliminary screening of 79-156 and 96-100 parental genotypes using SSR markers developed from cabbage sequence scaffolds and $B$. oleracea ESTs identified 252 polymorphic markers between the two parents. Of these polymorphic markers, 149 were used to genotype 157 members of the $\mathrm{DH}$ population. In addition to 12 EST-SSR markers, 123 scaffold-SSR markers were incorporated into the DH linkage map. The linkage analysis uncovered nine linkage groups. Based on the presence of reference SSR markers, the linkage groups were designated as $\mathrm{C} 1-\mathrm{C} 9$ in accordance with the nomenclature used by Wang et al. (2012a) and Lv et al. (2014).

The framework linkage map (Fig. 4) was $906.62 \mathrm{cM}$ in length, with an average betweenmarker distance of $6.72 \mathrm{cM}$, a minimum

Table 1. Statistical summary of head splitting resistance in parents, $\mathrm{F}_{1}, \mathrm{RF}_{1}$, and doubled haploid (DH) populations.

\begin{tabular}{|c|c|c|c|c|c|c|c|c|c|}
\hline \multirow[b]{2}{*}{ Head-splitting index } & \multicolumn{4}{|c|}{ Parents, $F_{1}$ and $\mathrm{RF}_{1}$} & \multicolumn{5}{|c|}{ DH populations } \\
\hline & $\overline{79-156}$ & $96-100$ & $\mathrm{~F}_{1}$ & $\mathrm{RF}_{1}$ & $\overline{\text { Mean }}$ & SD & Variation range & Skewness & Kurtosis \\
\hline 2012 & $85.32 \mathrm{c}$ & $9.36 \mathrm{a}$ & $33.12 \mathrm{~b}$ & $32.28 \mathrm{~b}$ & 30.45 & 28.55 & $0.00-100$ & 0.97 & -0.29 \\
\hline
\end{tabular}

${ }^{\mathrm{z}}$ Values within a given row followed by the same lowercase letter are not significantly different $(P<0.05)$ according to Duncan's multiple range test. 
between-marker distance of $0.46 \mathrm{cM}$, and a maximum distance of $34.90 \mathrm{cM}$. The largest linkage group, encompassing $189.46 \mathrm{cM}$, was C3; the smallest, C2, spanned $32.01 \mathrm{cM}$ (Table 5). The maximum average distance between markers $(10.67 \mathrm{cM})$ was that of $\mathrm{C} 2$, which featured the lowest number of markers (3); the minimum average distance (3.34 cM) was found on $\mathrm{C} 7$, which had the highest number of markers (24). The cabbage genome has been variously estimated to comprise 603 (Uzunova et al., 1995) or $630 \mathrm{Mbp}$ (Liu et al., 2014). Using the latest estimate of Liu et al. (2014), the average physical distance between mapped markers was calculated to be $4.67 \mathrm{Mbp}$.

Segregation distortion in the $\mathrm{DH}$ population. Segregation distortion is a feature common to Brassica DH populations, indicating possible preferential selection of genotypes responsive to microspore culture and/or the ability to produce seed during regeneration and seed-bulking phases (Sebastian et al., 2000; Wang et al., 2012a). Based on a $\chi^{2}$ test for goodness of fit to the expected 1:1 Mendelian segregation ratio, 90 of 135 loci displayed varying degrees of distortion $(P \leq 0.01)$ (Table 5). Although slightly more, $79-156$ alleles $(63.3 \%)$, were present among the 90 distorted loci compared with 96-100 (36.7\%) alleles (Table 5), there was not a significant departure from a $1: 1$ Mendelian ratio. Linkage groups $\mathrm{C} 1, \mathrm{C} 4$, and C9 had clusters of markers that were distorted toward 96-100 alleles, whereas linkage groups C3, C5, C6, and C7 contained clusters of markers distorted in favor of 79-156. Linkage group C8 included small clusters of both parental genotypes. No heterozygous loci were scored during genotyping of the molecular markers.

QTL mapping for HSR in cabbage. As shown in Table 6 and Fig. 4, eight QTLs for HSR during 2 years were detected using MQM and ICIM methods with Map QTL 4.0 and IciMapping 3.0 software. The QTLs were located on cabbage chromosomes $\mathrm{C} 4$, C6, C7, and C9 and individually explained $5.50 \%$ to $13.94 \%$ of observed phenotypic variation. Using the MQM program, six QTLs were detected on chromosomes C4, C7, and C9; these QTLs collectively accounted for $38.4 \%$ and $38.0 \%$ of the phenotypic variation in 2011 and 2012, respectively, with the

Table 2. Analysis of variance of head splitting resistance (HSR) in the doubled haploid population.

\begin{tabular}{llrrrc}
\hline Yr & \multicolumn{1}{c}{ Source } & DF & \multicolumn{1}{c}{$S S$} & \multicolumn{1}{c}{$M S$} & $F$ \\
\hline 2011 & Block & 13 & $44,468.71$ & $3,420.67$ & 152.81 \\
& Line & 141 & $346,887.36$ & $2,460.19$ & $109.91^{* *}$ \\
& Replication & 2 & 89.02 & 44.51 & 1.99 \\
& Block $\times$ rep & 26 & 557.36 & 21.44 & 0.96 \\
& Error & 282 & $6,312.42$ & 22.38 & \\
& Corrected total & 464 & $398,314.87$ & & \\
& Block & 10 & $41,866.24$ & $4,186.62$ & 117.53 \\
& Line & 169 & $402,077.30$ & $2,379.16$ & $66.79^{* *}$ \\
& Replication & 2 & 95.09 & 47.54 & 1.33 \\
& Block $\times$ rep & 20 & 664.32 & 33.22 & 0.93 \\
& Error & 338 & $12,040.46$ & 35.62 & \\
& Corrected total & 539 & $456,743.42$ & & \\
& Year & 1 & 784.70 & 784.70 & $5.78^{*}$ \\
& Line & 154 & $236,825.86$ & $1,537.83$ & $11.34^{* *}$ \\
& Error & 154 & $20,891.50$ & 135.66 & \\
\hline
\end{tabular}

$*$ and $* *$ indicate significant differences at $P<0.05$ and $P<0.01$, respectively. SS, sum of squares; $\mathrm{DF}$, degree of freedom; MS, mean squares; F, Fisher. effect of each QTL ranging from 7.1 to $12.1 \%$ over the 2 years. Hsr 4.2 and $H s r$ 7.2, which were robust QTLs showing a relatively large effect, could be detected in both years and were distributed between markers Scaffold12597a/Scaffold55516 and Scaffold195/ Scaffold46873. In both years, the 96-100 allele at the Hsr 4.2 locus increased the tendency toward HSR, whereas this allele at the Hsr 7.2 locus decreased it. Using ICIM, five of the same QTLs were detected on chromosomes $\mathrm{C} 4, \mathrm{C} 6$, and $\mathrm{C} 9$ and together explained $37.6 \%$ and $46.7 \%$ of observed phenotypic variation in 2011 and 2012, respectively. Their individual effects ranged from $5.5 \%$ to $13.9 \%$ - the same trend observed using MQM. Three of the QTLs (Hsr 4.2, Hsr 9.2, and Hsr 9.3) either overlapped or were adjacent to the corresponding regions detected using MQM. Hsr 9.3 was located in the interval between BOE344 BOE975 on chromosome C9; it explained $10.1 \%$ to $13.9 \%$ of the phenotypic variation and showed the largest effect of the three QTLs. The locus Hsr 9.1, detected only by ICIM, was a major QTL explaining $9.2 \%$ to $10.5 \%$ of the phenotypic variation in both years. The 96-100 allele increased HSR at the $\mathrm{Hsr} 9.3$ locus and decreased it at $\mathrm{Hsr} 9.1 \mathrm{in}$ both years.

\section{Discussion}

Genetic analysis. HSR is an important agronomic trait, being associated with appearance, yield, mechanical harvestability, marketability, and storability. Qin et al. (1994) have reported that head splitting in cabbage under water-sufficient conditions is mainly due to genetic factors. In the present study, head splitting is mainly controlled by genetic features, with environmental conditions having a lesser influence. Similar results have been recorded for chinese cabbage as well as watermelon, tomato, and various other fruit crops cracking (Budan, 1999; Cortés et al., 1983). The development of

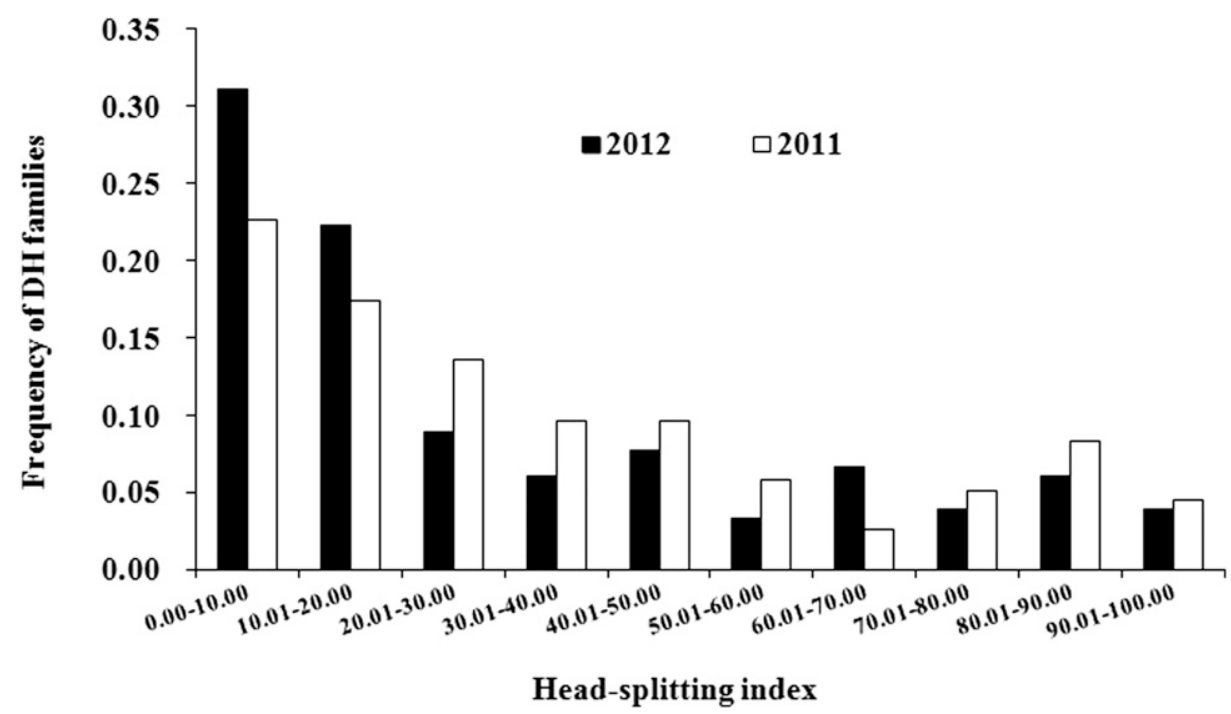

Fig. 3. Frequency distribution of head-splitting index in DH families in 2011 and 2012, arrows indicate the mean head-splitting index of the parental lines. 
Table 3. Akaike information criterion (AIC) values estimated for different genetic models.

\begin{tabular}{|c|c|c|c|c|c|}
\hline \multirow[b]{2}{*}{ Model } & \multicolumn{2}{|c|}{ AIC } & \multirow[b]{2}{*}{ Model } & \multicolumn{2}{|c|}{$\mathrm{AIC}$} \\
\hline & 2011 & 2012 & & 2011 & 2012 \\
\hline$\overline{\mathrm{A}-0}$ & 1576.176 & 1829.380 & E-2-0 & 1442.933 & 1724.153 \\
\hline A-1 & 1477.031 & 1733.070 & E-2-1 & 1442.181 & 1722.841 \\
\hline B-1-1 & 1448.086 & 1736.838 & E-2-2 & 1467.829 & 1722.419 \\
\hline$\underline{B-1-2}$ & 1439.054 & $\underline{1678.730}$ & E-2-3 & 1446.232 & 1692.444 \\
\hline$\overline{\mathrm{B}-1-3}$ & 1464.138 & $\overline{1695.314}$ & E-2-4 & 1440.953 & 1721.049 \\
\hline $\mathrm{C}-0$ & 1533.019 & 1778.552 & E-2-5 & 1440.953 & 1721.049 \\
\hline C-1 & 1541.363 & 1788.985 & E-2-6 & 1465.257 & 1720.842 \\
\hline D-0 & 1464.339 & 1719.479 & E-2-7 & 1465.042 & 1719.195 \\
\hline D-1 & 1463.836 & 1718.423 & E-2-8 & 1465.042 & 1719.196 \\
\hline E-1-0 & 1440.924 & 1723.253 & E-2-9 & 1534.623 & 1779.918 \\
\hline E-1-1 & 1440.172 & 1721.397 & $\underline{F-1}$ & 1438.600 & $\underline{1683.141}$ \\
\hline E-1-2 & 1465.832 & 1720.422 & $\overline{\mathrm{F}-2}$ & 1426.862 & $\overline{1708.692}$ \\
\hline E-1-3 & 1453.709 & 1689.240 & $\overline{\mathrm{F}-3}$ & $\overline{1444.692}$ & 1691.289 \\
\hline E-1-4 & 1438.942 & 1719.573 & F-4 & 1558.399 & 1713.401 \\
\hline E-1-5 & 1438.942 & 1719.573 & G-0 & 1434.154 & 1677.556 \\
\hline E-1-6 & 1463.393 & 1719.397 & $\overline{\mathrm{G}-1}$ & $\overline{1433.911}$ & $\overline{1678.578}$ \\
\hline E-1-7 & 1463.114 & 1717.723 & $\overline{\mathrm{G}-2}$ & $\overline{1465.797}$ & $\overline{1720.432}$ \\
\hline E-1-8 & 1463.114 & 1717.723 & G-3 & 1461.501 & 1779.675 \\
\hline E-1-9 & 1532.740 & 1778.148 & G-4 & 1455.627 & 1691.234 \\
\hline
\end{tabular}

Underlined models were selected as candidate models because of their smaller AIC values.

Table 4. Estimates of genetic parameters under the G-0 model over 2 years

\begin{tabular}{|c|c|c|c|c|c|c|c|c|}
\hline \multirow{2}{*}{$\begin{array}{l}\text { Distribution } \\
\text { parameter }\end{array}$} & \multicolumn{2}{|c|}{ Estimate } & \multirow{2}{*}{$\begin{array}{l}\text { First order } \\
\text { parameter }\end{array}$} & \multicolumn{2}{|c|}{ Estimate } & \multirow{2}{*}{$\begin{array}{l}\text { Second order } \\
\text { parameter }\end{array}$} & \multicolumn{2}{|c|}{ Estimate } \\
\hline & 2011 & 2012 & & 2011 & 2012 & & 2011 & 2012 \\
\hline$\mu_{1}$ & 90.57 & 90.62 & $m$ & 37.78 & 32.93 & $\sigma_{\mathrm{p}}^{2}$ & 512.54 & 581.13 \\
\hline$\mu_{2}$ & 79.43 & 65.17 & $d_{\mathrm{a}}$ & 20.4 & 20.13 & $\sigma_{\mathrm{mg}}^{2}$ & 451.22 & 512.70 \\
\hline$\mu_{3}$ & 32.23 & 12.80 & $d_{\mathrm{b}}$ & 8.59 & 7.04 & $\sigma_{p g}^{2}$ & 38.94 & 32.81 \\
\hline$\mu_{4}$ & 12.44 & 12.80 & $d_{\mathrm{c}}$ & 15.89 & 12.42 & $\sigma^{2}$ & 22.38 & 35.62 \\
\hline$\mu_{5}$ & 50.25 & 43.65 & $i_{\mathrm{ab}}$ & 3.64 & 7.04 & $h_{\mathrm{mg}}^{2}(\%)$ & 88.03 & 88.22 \\
\hline$\mu_{6}$ & 12.44 & 12.80 & $i_{\mathrm{ac}}$ & 10.94 & 12.42 & $h_{\mathrm{pg}}^{2}(\%)$ & 7.60 & 5.65 \\
\hline$\mu_{7}$ & 12.42 & 12.80 & $i_{\mathrm{bc}}$ & -0.86 & -0.67 & & & \\
\hline$\mu_{8}$ & 12.42 & 12.80 & $i_{\mathrm{abc}}$ & -5.81 & -0.68 & & & \\
\hline
\end{tabular}

$\sigma_{\mathrm{p}}{ }^{2}$, phenotypic variation; $\sigma_{\mathrm{mg}}{ }^{2}$, major gene variation; $\sigma_{\mathrm{pg}}{ }^{2}$, polygenic variation; $\sigma^{2}$, environmental variation; $h_{\mathrm{mg}}^{2}$, major gene heritability; $h_{\mathrm{pg}}^{2}$, polygene heritability.

Table 5. Distribution of simple sequence repeat molecular markers on the genetic map.

\begin{tabular}{|c|c|c|c|c|c|c|c|c|}
\hline \multirow{2}{*}{$\begin{array}{l}\text { Linkage } \\
\text { group }\end{array}$} & \multirow{2}{*}{$\begin{array}{l}\text { Length } \\
(\mathrm{cM})\end{array}$} & \multirow{2}{*}{$\begin{array}{l}\text { Number of } \\
\text { markers }\end{array}$} & \multicolumn{3}{|c|}{$\begin{array}{l}\text { Between marker } \\
\text { interval }(\mathrm{cM})\end{array}$} & \multirow{2}{*}{$\begin{array}{c}\text { No. of distorted } \\
\text { makers }(P \leq 0.05)\end{array}$} & \multicolumn{2}{|c|}{ No. of alleles } \\
\hline & & & Min & Max & Avg & & $79-156$ & $96-100$ \\
\hline$\overline{\mathrm{C} 1}$ & 64.15 & 16 & 1.32 & 12.19 & 4.01 & 11 & 0 & 11 \\
\hline $\mathrm{C} 2$ & 32.01 & 3 & 15.83 & 16.17 & 10.67 & 1 & 1 & 0 \\
\hline $\mathrm{C} 3$ & 189.46 & 19 & 0.46 & 19.08 & 9.97 & 16 & 16 & 0 \\
\hline $\mathrm{C} 4$ & 111.43 & 16 & 3.23 & 16.44 & 6.96 & 8 & 0 & 8 \\
\hline $\mathrm{C} 5$ & 93.88 & 13 & 3.32 & 18.73 & 7.22 & 9 & 9 & 0 \\
\hline C6 & 88.23 & 9 & 5.10 & 23.07 & 9.8 & 8 & 8 & 0 \\
\hline C7 & 80.07 & 24 & 0.97 & 7.94 & 3.34 & 16 & 15 & 1 \\
\hline C8 & 92.81 & 19 & 1.06 & 12.46 & 4.88 & 12 & 8 & 4 \\
\hline C9 & 154.57 & 16 & 3.67 & 34.90 & 9.66 & 9 & 0 & 9 \\
\hline Total & 906.62 & 135 & - & - & - & 90 & 57 & 33 \\
\hline
\end{tabular}

varieties having HSR is thus an essential strategy for breeders.

Few relevant genetic analyses have been conducted, however, and previous genetic studies (Chiang, 1972; Zhuang et al., 2009) of HSR inheritance have focused only on HSR as a polygenic system and ignored the effect of individual genes. The major gene/ polygene genetic segregation analysis, used in the present study, has the ability of determining individual effects up to major genes and the collective epistatic effects of polygene (Wang et al., 2001). It is strongly recommended for plant breeders to apply it as a simple and useful technique to know the number of major genes, their kinds of genetic effects, heritability values and genetic information on all kinds of genetic effects, and heritability value of whole polygenes without any extra requirements on laboratory conditions except a precise experiment (Gai et al., 2007). It was used for head cracking in our previous study with six basic generations (Su et al., 2012). However, the present approach designed for the six basic populations was only capable to find the genetic mechanism up to two major genes plus polygenes (Gai et al., 2003) and the separation generations can't be repeated, which may lead to large errors. In this study, we performed a segregation analysis of the HSR trait using a DH population comprising more than 150 lines with three replications over 2 years. HSR is primarily controlled by hereditable factors with the additive-epistatic effects of three major genes as well as polygenes, and no cytoplasmic effect was observed. Additive effects predominated overall other types of genetic effects, and, as in previous studies, higher heritabilities of the trait were recorded with respect to major genes than polygenes (Chiang, 1972; Su et al., 2012; Zhuang et al., 2009).

Strategic considerations and $Q T L$ research. Compared with $\mathrm{F}_{2}$, DH populations are ideal for the genetic study of quantitative traits, because they are composed of genetically fixed DH lines, which can be replicated between test sites and trialed over years, decreasing the standard error of QTL genotype means and allowing a better estimate of trait heritability and increased power to detect QTLs (Soller and Beckmann, 1990). Although the number of available polymorphic loci may be reduced using intracrop crosses, such a strategy - as pointed out by Walley et al. (2012) - allows a direct relationship to be established between trait and crop type; the genetic variation captured in this fashion reduces the time required to incorporate important agronomic traits into elite breeding material. Here, we report a new cabbage linkage map using SSR markers in a DH population derived from an intrasubspecies cross of cabbage. Our newly constructed map and the generated DH lines are therefore not only important for research on related characteristics of cabbage, but will also contribute to the exchange of materials between laboratories and successive research in the future (Walley et al., 2012; Wang et al., 2012a)

With the advent of molecular markers, QTL mapping has become increasingly important in molecular breeding. Markerassisted selection and gene discovery are now widely used for the breeding of field crops and vegetables (Cheng et al., 2011; Sabouri, 2009; Walley et al., 2012). Although some QTLs have been identified in cabbage, research is still at a preliminary stage: QTL cloning has not yet been reported and functional analysis studies are rare ( $\mathrm{Lv}$ et al., 2014). For cabbage breeders, HSR is an important characteristic that affects both cabbage yield and quality, but no QTL studies have previously been reported for this trait.

The use of different genetic models, algorithms, and mapping procedures can produce different mapping results, even for the same set of data (Su et al., 2010). The results of different mapping methods can potentially complement one another. Whole-genome scanning with multiple mapping methods has thus been recommended for QTL mapping (Xing et al., 2012). Using data obtained over multiple years increases environmental heterogeneity and also allows improved estimates of QTLs that may not reach the genome-wide significance threshold in just one environment (Chen et al., 2010b; Piepho, 2005; Van Eeuwijk et al., 2010). We used two 
$\mathrm{C} 1$
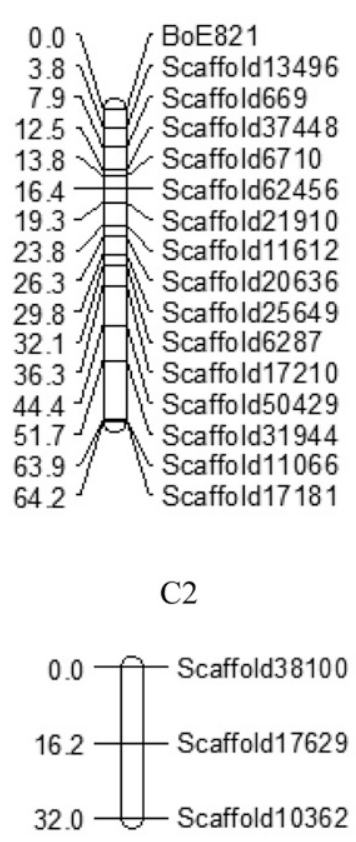

C6

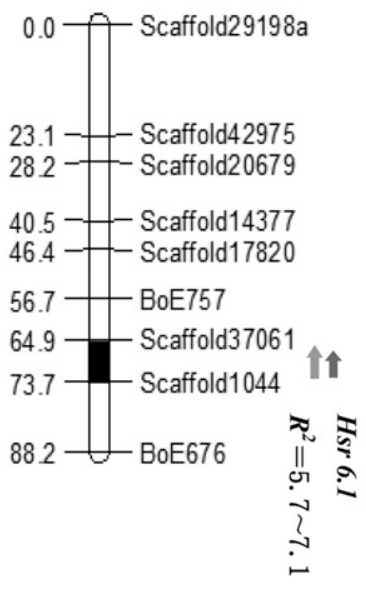

$\mathrm{C} 3$

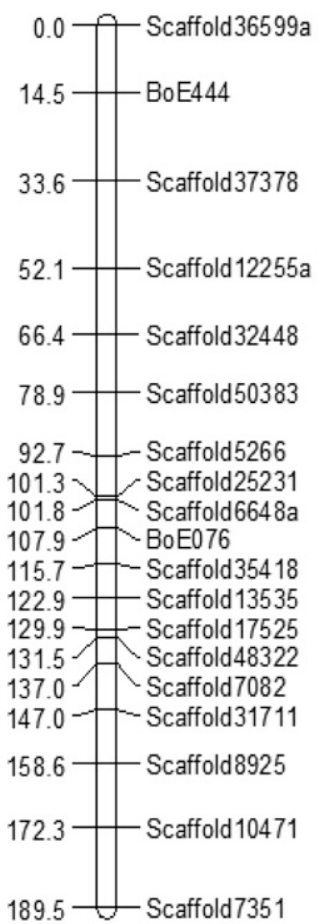

$\mathrm{C} 4$

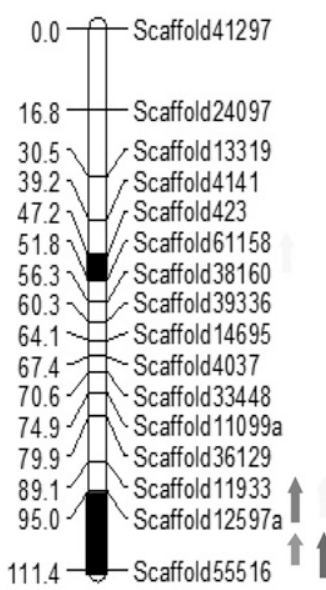

C5

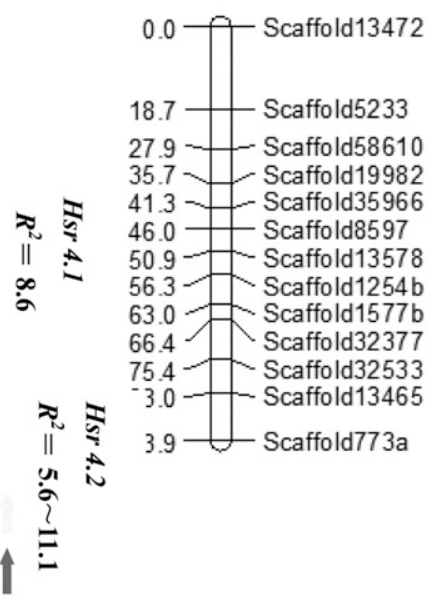

$\mathrm{C} 8$

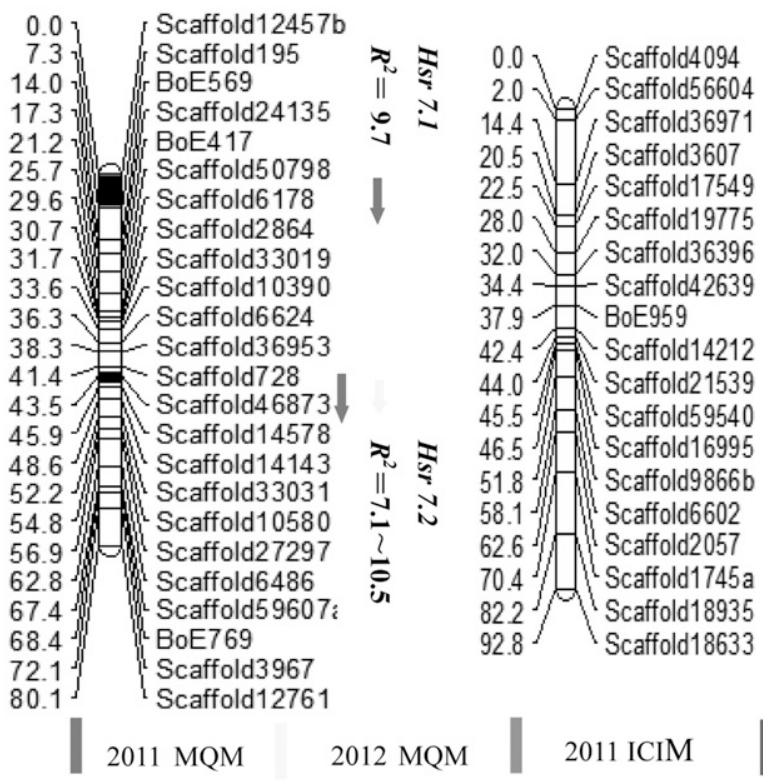

C9

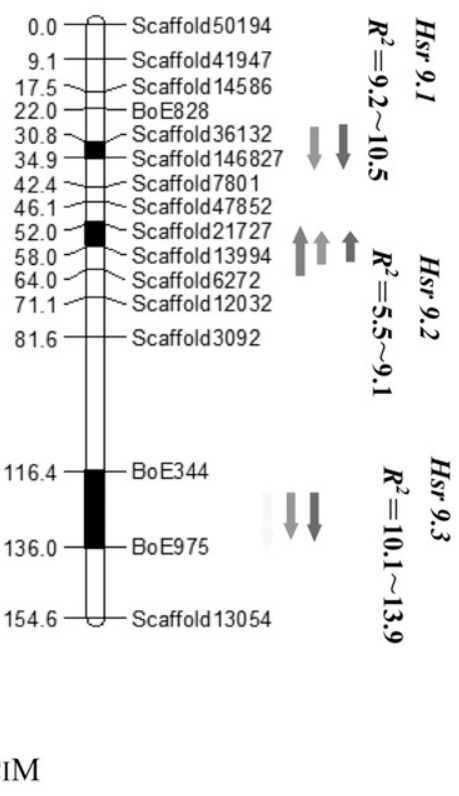

Fig. 4. Genetic linkage map and positions of quantitative trait loci (QTLs) associated with heading splitting resistance in a cabbage DH population. Marker locations are listed to the right and recombination distances $(\mathrm{cM})$ to the left of each linkage group. Locations of QTLs are indicated by names and arrows to the right of the linkage groups. Arrows indicate the relative effect of the 96-100 allele with upward for increasing and downward for decreasing. Red, yellow, green, and blue represent MQM and ICIM method in 2011, 2012, respectively. $\mathrm{R}^{2}$ means proportion of the phenotypic variation explained by each QTL.

mapping methods to analyze agronomic trait data collected during 2 years in a DH population, and our study results, the first to identify QTLs associated with the HSR trait in cabbage, provide support for the abovementioned assertions. For example, QTLs distributed on $\mathrm{C} 7$ and $\mathrm{C} 6$ were only identified by one mapping method; in addition, $\mathrm{Hsr} 9.2$ and $H_{s r} 9.3$ could both be detected in 2011 and 2012 by ICIM, but only one was identi- fied using MQM. On chromosome C9, QTL $H s r 9.1$ with a larger effect is physically quite close to Hsr 9.2. Whether these QTLs are independent or instead both components of a larger QTL is an open question. In brief, three or four major QTLs (Hsr 4.2, Hsr 7.2, Hsr 9.3, and/or Hsr 9.1) and some minor QTLs were detected over 2 years using the two mapping methods. This result is consistent with the results of classical genetic analysis, both segregation analysis and QTL mapping with molecular markers can be used as a mutual control and supplement (Gai et al., 2007).

Because cabbage lines resistant to head splitting have traditionally been selected in the field during the mature stage, splitting severity depends on environmental factors and plant conditions. The use of DNA markers enables reliable selection of resistant plants, 
Table 6. Analysis of quantitative trait loci (QTLs) for head splitting resistance in a cabbage doubled haploid (DH) population using multiple-QTL mapping (MQM) and inclusive composite interval mapping (ICIM) approaches.

\begin{tabular}{|c|c|c|c|c|c|c|c|}
\hline$\overline{\mathrm{Yr}}$ & QTL names ${ }^{\mathrm{z}}$ & Linkage group & Position (cM) & LOD & Marker interval & $R^{2}(\%)^{y}$ & $\operatorname{Add}^{x}$ \\
\hline & Hsr 4.2 & $\mathrm{C} 4$ & 100.0 & 3.01 & Scaffold12597a-Scaffold55516 & 9.1 & 9.19 \\
\hline & Hsr 7.2 & $\mathrm{C} 7$ & 43.5 & 4.3 & Scaffold195-Scaffold46873 & 10.5 & -10.81 \\
\hline 2011 (MQM) & Hsr 9.2 & C9 & 51.1 & 3.38 & Scaffold47852-Scaffold 21727 & 9.1 & 10.84 \\
\hline & Hsr 4.2 & $\mathrm{C} 4$ & 95.0 & 3.61 & Scaffold12597a-Scaffold55516 & 10.2 & 8.81 \\
\hline & Hsr 7.2 & $\mathrm{C} 7$ & 41.4 & 2.48 & Scafford728-Scaffold46873 & 7.1 & -7.62 \\
\hline \multirow[t]{3}{*}{2012 (MQM) } & Hsr 9.3 & C9 & 126.4 & 3.06 & BOE344-B0E975 & 12.1 & -12.93 \\
\hline & Hsr 9.1 & C9 & 34.0 & 2.84 & Scaffold36132-Scaffold146827 & 9.2 & -9.08 \\
\hline & Hsr 9.2 & C9 & 58.0 & 2.54 & Scaffold21727-Scaffold13994 & 5.6 & 7.18 \\
\hline \multirow[t]{5}{*}{2011 (ICIM) } & Hsr 9.3 & C9 & 128.0 & 3.60 & BoE344-BoE975 & 10.1 & -9.38 \\
\hline & Hsr 4.2 & $\mathrm{C} 4$ & 95.0 & 5.41 & Scaffold12597a- Scaffold55516 & 11.1 & 9.15 \\
\hline & Hsr 6.1 & C6 & 66.0 & 2.67 & Scaffold37061-Scaffold1044 & 5.7 & 6.86 \\
\hline & Hsr 9.1 & C9 & 34.0 & 3.54 & Scaffold36132-Scaffold146827 & 10.6 & -9.14 \\
\hline & Hsr 9.2 & C9 & 58.0 & 2.79 & Scaffold21727-Scaffold13994 & 5.5 & 6.76 \\
\hline
\end{tabular}

${ }^{\mathrm{z}} \mathrm{QTLs}$ are named according to the trait (i.e., $H s r$, head splitting resistance) followed by the chromosome number and position.

${ }^{\mathrm{y}}$ Proportion of the phenotypic variation explained by each QTL.

${ }^{x}$ Additive effect: positive and negative values indicate that parental lines 96-100 and 79-156 respectively bear the HSR-enhancing allele.

even at the seedling stage. The makers link to QTLs identified in our study will be helpful for the identification of genes related to HSR and for MAS in cabbage breeding programs.

\section{Literature Cited}

Akaike, H. 1977. On entropy maximisation principle, p. 27-47. In: P.R. Krishnaiah (ed.). Proceedings of the Symposium on Applications of Statistics. Amsterdam, The Netherlands.

Anbessa, Y., T. Warkentin, A. Vandenberg, and R. Ball. 2006. Inheritance of time to flowering in chickpea in a short-season temperate environment. J. Hered. 97:55-61.

Brant, J.B., C.A. Gustavo, and M.G. Peter. 1991. Fast and sensitive silver staining of DNA in polyacrylamide gels. Anal. Biochem. 196:80-83.

Brown, A.F., G.G. Yousef, K.K. Chebrolu, R.W. Byrd, K.W. Everhart, A. Thomas, R.W. Reid, I.A.P. Parkin, A.G. Sharpe, R. Oliver, I. Guzman, and E.W. Jackson. 2014. High-density single nucleotide polymorphism (SNP) array mapping in Brassica oleracea: Identification of QTL associated with carotenoid variation in broccoli florets. Theor. Appl. Genet. 127(9): 2051-2064.

Budan, S. 1999. Evaluation of the natural susceptibility and artificially induced fruit cracking of hundred sour cherry cultivars. Eucarpia symposium on Fruit Breed. and Genet. 538: 123-130.

Chen, C., M. Zhuang, K.N. Li, Y.M. Liu, L.M. Yang, Y.Y. Zhang, F. Cheng, P.T. Sun, and Z.Y. Fang. 2010a. Development and utility of EST-SSR marker in cabbage. Acta. Hort. Sinica. 37(2):221-228. [in Chinese with English summary].

Chen, X., F. Zhao, and S. Xu. 2010b. Mapping environment-specific quantitative trait loci. Genet. 186:1053-1066.

Cheng, L.R., Y. Wang, C.B. Zhang, C.X. Wu, J.L. Xu, H.Y. Zhu, J.T. Leng, Y.N. Bai, R.X. Guan, W.S. Hou, L.J. Zhang, and T.F. Han. 2011. Genetic analysis and QTL detection of reproductive period and post-flowering photoperiod responses in soybean. Theor. Appl. Genet. 123:421-429.

Chiang, M.S. 1972. Inheritance of head splitting in cabbage (Brassica oleracea var. capitata). Euphytica 21:507-509.
Cortés, C., M. Ayuso, G. Palomares, J. Cuartero, and F. Nuez. 1983. Relationship between radial and concentric cracking of tomato fruit. Sci. Hort. 21:323-328.

Fahey, J.W. and P. Talalay. 1995. The role of crucifers in cancer chemoprotection, p. 87-93. In: D.L. Gustin and H.E. Rockville (eds.). Phytochemicals and health, American Society of Plant Physiologists, Rockville.

Gao, M., G. Li, B. Yang, D. Qiu, M. Farnham, and C. Quiros. 2007. High-density Brassica oleracea linkage map: Identification of useful new linkages. Theor. Appl. Genet. 115:277-287.

Gai, J.Y. 2000. Experimentation method. China Agriculture Press, Beijing, China.

Gai, J.Y., Y.M. Zhang, and J.K. Wang. 2003. Genetic system of quantitative traits in plants. Science Press, Beijing.

Gai, J.Y. 2006. Segregation analysis on genetic system of quantitative traits in plants. Front. Biol. China 1:85-92.

Gai, J.Y., Y.J. Wang, X.L. Wu, and S.Y. Chen. 2007. A comparative study on segregation analysis and QTL mapping of quantitative traits in plants-with a case in soybean. Front. Agr. China 1:1-7

Hao, J.J., S.X. Yu, Q.X. Ma, S.L. Fan, and M.Z. Song. 2008. Inheritance of time of flowering in upland cotton under natural conditions. Plant Breeding 127:383-390.

Holt, J.E. and D. Schoorl. 1983. Cracking and energy dissipation in cabbages. J. Texture Stud. 14:99-111.

Kifuji, Y., H. Hanzawa, Y. Terasawa, Ashutosh, and T. Nishio. 2012. QTL analysis of black rot resistance in cabbage using newly developed EST-SNP markers. Euphytica 196:289-295.

Lan, T.H. and A.H. Paterson. 2001. Comparative mapping of QTLs determining the plant size of Brassica oleracea. Theor. Appl. Genet. 103:383-397.

Liang, H.Z., Y.L. Yu, H.Q. Yang, L.J. Xu, W. Dong, H. Du, W.W. Cui, and H.Y. Zhang. 2014. Inheritance and QTL mapping of related root traits in soybean at the seedling stage. Theor. Appl. Genet. 127(10):2127-2137.

Li, H.H., G.Y. Ye, and J.K. Wang. 2007. A modified algorithm for the improvement of composite interval mapping. Genet. 175:361374.

Lv, H.H., Q.B. Wang, Y.Y. Zhang, L.M. Yang, Z.Y. Fang, X.W. Wang, Y.M. Liu, M. Zhuang,
Y. Lin, H.L. Yu, and B. Liu. 2014. Linkage map construction using InDel and SSR markers and QTL analysis of heading traits in Brassica oleracea var. capitata L. Mol. Breeding 34:87-98.

Liu, H., E.H. Zhang, Z.M. Xu, Y.A. Cheng, and H.W. Li. 2009. Impact of three main cultivated factors on the character of spring cabbage dehiscent leafy head. J. Northwest A \& F University-Natural Sci. Educ. 37:120-124. [in Chinese with English summary].

Liu, S.Y., Y.M. Liu, X.H. Yang, C.B. Tong, D. Edwards, I. Parkin, M.X. Zhao, J.X. Ma, J.Y. Yu, S.M. Huang, X.Y. Wang, J.Y. Wang, K. Lu, Z.Y. Fang, I. Bancroft, T. Yang, Q. Hu, X.F. Wang, Z. Yue, H.J. Li, L.F. Yang, J. Wu, Q. Zhou, W.X. Wang, G. King, P. Chris, C.X. Lu, Z.Y. Wu, P. Sampath, Z. Wang, H. Guo, S.K. Pan, L.M. Yang, J.M. Min, D. Zhang, D. Jin, W.S. Li, H. Belcram, J.X. Tu, M. Guan, C.K. Qi, D.Z. Du, J.N. Li, L.C. Jiang, J. Batley, A. Sharpe, B. Park, P. Ruperao, F. Cheng, N. Waminal, Y. Huang, C.H. Dong, L. Wang, J.P. Li, Z.Y. Hu, M. Zhuang, Y. Huang, J.Y. Huang, J.Q. Shi, D.S. Mei, J. Liu, T. Lee, J.P. Wang, H.Z. Jin, Z.Y. Li, X. Li, J. Zhang, L. Xiao, Y.M. Zhou, Z.S. Liu, X.Q. Liu, and R. Qin. 2014. The Brassica oleracea genome reveals the asymmetrical evolution of polyploid genomes. Nat. Commun. doi: 10.1038/ ncomms 4930 .

Masarirambi, M.T., T.O. Oseni, V.D. Shongwe, and N. Mhazo. 2011. Physiological disorders of Brassicas/Cole crops found in Swaziland: A review. Afr. J. Plant Sci. 5(1):8-14.

Mei, J.Q., Y.G. Ding, K. Lu, D.Y. Wei, Y. Liu, J.O. Disi, J.N. Li, L.Z. Liu, S.Y. Liu, J. McKay, and W. Qian. 2013. Identification of genomic regions involved in resistance against Sclerotinia sclerotiorum from wild Brassica oleracea. Theor. Appl. Genet. 126:549-556.

Nagaoka, T., M.A.U. Doullah, S. Matsumoto, S. Kawasaki, T. Ishikawa, H. Hori, and K. Okazaki. 2010. Identification of QTLs that control clubroot resistance in Brassica oleracea and comparative analysis of clubroot resistance genes between $B$. rapa and B. oleracea. Theor. Appl. Genet. 120:1335-1346.

Okazaki, K., K. Sakamoto, R. Kikuchi, A. Saito, E. Togashi, Y. Kuginuki, S. Matsumoto, and M. Hirai. 2007. Mapping and characterization of FLC homologs and QTL analysis of flowering 
time in Brassica oleracea. Theor. Appl. Genet. 114:595-608.

Piepho, H.P. 2005. Statistical tests for QTL and QTL-by-environment effects in segregating populations derived from line crosses. Theor. Appl. Genet. 110:561-566.

Pink, D., L. Bailey, S. McClement, P. Hand, E. Mathas, V. Buchanan-Wollaston, D. Astley, G. King, and G. Teakle. 2008. Double haploids, markers and QTL analysis in vegetable brassicas. Euphytica 164:509-514.

Qin, Z.W., L.J. Wang, C. Wang, and R.X. Xu. 1994. Studies on character of cabbage dehiscent leafy head. J. Northeast Agr. Univ. 25:344-346. [in Chinese with English summary].

Sabouri, H. 2009. QTL detection of rice grain quality traits by microsatellite markers using an indica rice (Oryza sativa L.) combination. J. Genet. 88(1):81-85.

Saghai-Maroof, M.A., K.M. Soliman, R.A. Jorgensen, and R.W. Allard. 1984. Ribosomal DNA spacerlength polymorphisms in barley: Mendelian inheritance, chromosomal location, and population dynamics. Proc. Natl. Acad. Sci. USA 81:8014-8018.

Sebastian, R., E. Howell, G. King, D. Marshall, and M. Kearsey. 2000. An integrated AFLP and RFLP Brassica oleracea linkage map from two morphologically distinct doubled-haploid mapping populations. Theor. Appl. Genet. 100(1): 75-81.

Simon, M., O. Loudet, S. Durand, A. Berard, D. Brunel, F.X. Sennesal, M. Durand-Tardif, G. Pelletier, and C. Camilleri. 2008. Quantitative trait loci mapping in five new large recombinant inbred line populations of Arabidopsis thaliana genotyped with consensus singlenucleotide polymorphism markers. Genet. 178: 2253-2264.

Soller, M. and J.S. Beckmann. 1990. Marker-based mapping of quantitative trait loci using replicated progenies. Theor. Appl. Genet. 80:205208.

Su, C.F., T.J. Zhao, and J.Y. Gai. 2010. Simulation comparisons of effectiveness among QTL mapping procedures of different statistical genetic models. Acta Agron. Sin. 36:1100-1107. [in Chinese with English summary].

Su, Y.B., Y.M. Liu, Z.Y. Fang, L.M. Yang, M. Zhuang, Y.Y. Zhang, X.L. Zhang, and P.T. Sunday. 2012. Genetic analysis of headsplitting resistance traits in cabbage. Acta Hort. Sin. 39:1482-1490. [in Chinese with English summary].

Uzunova, M., W. Ecke, K. Weissleder, M. Uzunova, W. Ecke, K. Weissleder, and G. Röbbelen. 1995. Mapping the genome of rapeseed (Brassica napus L.). I. Construction of an RFLP linkage map and localization of QTLs for seed glucosinolate content. Theor. Appl. Genet. 90:194-204.

Van Eeuwijk, F.A., M.C. Bink, K. Chenu, and S.C. Chapman. 2010. Detection and use of QTL for complex traits in multiple environments. Curr. Opin. Plant Biol. 13:193-205.

Van Ooijen, J.W. 2006. JoinMap 4, software for the calculation of genetic linkage maps in experimental populations. Kyazma BV, Wageningen.

Van Ooijen, J.W., M.P. Boer, R.C. Jansen, and C. Maliepaard. 2002. Map QTL 4.0: Software for the calculation of QTL positions on genetic maps. Plant Res. Intl. Wageningen.

Wang, J., D. Podlich, M. Cooper, and I. DeLacy. 2001. Power of the joint segregation analysis method for testing mixed major-gene and polygene inheritance models of quantitative traits. Theor. Appl. Genet. 103:804-816.

Wang, W.X., S.M. Huang, Y.M. Liu, Z.Y. Fang, L.M. Yang, W. Hua, S.X. Yuan, S.Y. Liu, J.F. Sun, M. Zhuang, Y.Y. Zhang, and A.S. Zeng. 2012a. Construction and analysis of a highdensity genetic linkage map in cabbage (Brassica oleracea L. var. capitata). BMC Genomics 13:523-535.

Wang, W.Y., F. Zhang, X.Y. Yu, X.L. Shen, Y.Y. Ge, and Z. Zhang. 2012b. Genetic analysis and associated SRAP markers for horticultural traits of Aechmea bromeliads. Sci. Hort. 147: 29-33.

Walley, P.G., J. Carder, E. Skipper, E. Mathas, J. Lynn, and D.P.V. Buchanan-Wollaston. 2012. A new broccoli $\times$ broccoli immortal mapping population and framework genetic map: Tools for breeders and complex trait analysis. Theor. Appl. Genet. 124:467-484.

Xing, G.N., B. Zhou, Y.F. Wang, T.J. Zhao, D.Y. Yu, S.Y. Chen, and J.Y. Gai. 2012. Genetic components and major QTL confer resistance to bean pyralid (Lamprosema indicata Fabricius) under multiple environments in four RIL populations of soybean. Theor. Appl. Genet. 125:859-875.

Yuan, S.X., Y.M. Liu, Z.Y. Fang, L.M. Yang, M. Zhuang, Y.Y. Zhang, and P.T. Sunday. 2011. Effect of combined cold pretreatment and heat shock on microspore cultures in broccoli. Plant Breeding 130:80-85.

Yuan, S.X., Y.B. Su, Y.M. Liu, Z.Y. Fang, L.M Yang, M. Zhuang, Y.Y. Zhang, and P.T. Sunday. 2012. Effects of $\mathrm{pH}, \mathrm{MES}$, arabinogalactanproteins on microspore cultures in white cabbage. Plant Cell Tiss. Org. Cult. 110:69-76.

Zeng, A.S., Y.M. Liu, Z.Y. Fang, L.M. Yang, M. Zhuang, Y.Y. Zhang, and P.T. Sunday. 2009. Studies on relationship between splittingtolerant characteristics and surface microconfiguration and cell Tissue structure of leaf in cabbage (Brassica oleraca var. capitata). Acta Agr. Boreali-Sinica. S2:41-45. [in Chinese with English summary].

Zhang, F., S.M. Chen, F.D. Chen, W.M. Fang, Y. M. Deng, Q.S. Chang, and P.S. Liu. 2010. Genetic analysis and associated SRAP markers for flowering traits of chrysanthemum (Chrysanthemum morifolium). Euphytica 177:15-24.

Zhang, H.Y., H.W. Miao, L.B. Wei, C. Li, R.H. Zhao, and C.Y. Wang. 2013. Genetic analysis and QTL mapping of seed coat color in Sesame (Sesamum indicum L.). PLoS ONE 8:1-10.

Zhang, Y.M., J.Y. Gai, and Y.H. Yang. 2003. The EIM algorithm in the joint segregation analysis of quantitative traits. Genet. Res. 81:157163.

Zhuang, M., Y.Y. Zhang, Z.Y. Fang, Y.M. Liu, L. M. Yang, and P.T. Sunday. 2009. Studies on combining ability and heritability of splittingresistance characteristic in cabbage (Brassica oleracea var. capitata). China Veg. 2:12-15. [in Chinese with English summary]. 
Breeding, Cultivars, Rootstocks, and Germplasm Resources

Supplemental Table 1. Design of the field experiments.

\begin{tabular}{|c|c|c|c|c|c|c|c|c|c|c|c|c|c|c|c|c|c|c|c|}
\hline$\frac{\text { Year }}{2011}$ & \multicolumn{19}{|c|}{ The order of parents, $F_{1}, R F_{1}$ and the block number in each repeat of DHs } \\
\hline & III & $\mathrm{P}_{1}$ & $\mathrm{~F}_{1}$ & $\mathrm{RF}_{1}$ & $\mathrm{P}_{2}$ & 14 & 5 & 12 & 4 & 8 & 1 & 10 & 6 & 9 & 13 & 3 & 7 & 2 & 11 \\
\hline 2012 & I & $P_{1}$ & $\mathrm{P}_{2}$ & $\mathrm{~F}_{1}$ & $\mathrm{RF}_{1}$ & 1 & 5 & 6 & 11 & 9 & 7 & 2 & 3 & 10 & 4 & 8 & & & \\
\hline & III & $\mathrm{P}_{1}$ & $\mathrm{RF}_{1}$ & $\mathrm{~F}_{1}$ & $\mathrm{P}_{2}$ & 3 & 5 & 11 & 4 & 8 & 10 & 6 & 9 & 1 & 7 & 2 & & & \\
\hline
\end{tabular}

${ }^{2}$ Parents, $\mathrm{F}_{1}$, and $\mathrm{RF}_{1}$ plants were distributed according to a randomized complete block design with three replicates.

'Doubled haploid (DH) lines were first divided randomly into 14 blocks in 2011 and 11 blocks in 2012; the blocks were then distributed according to a randomized complete block design with three replicates.

Supplemental Table 2. Genetic models tested during joint segregation analysis of doubled haploid populations (adopted from Gai et al., 2003).

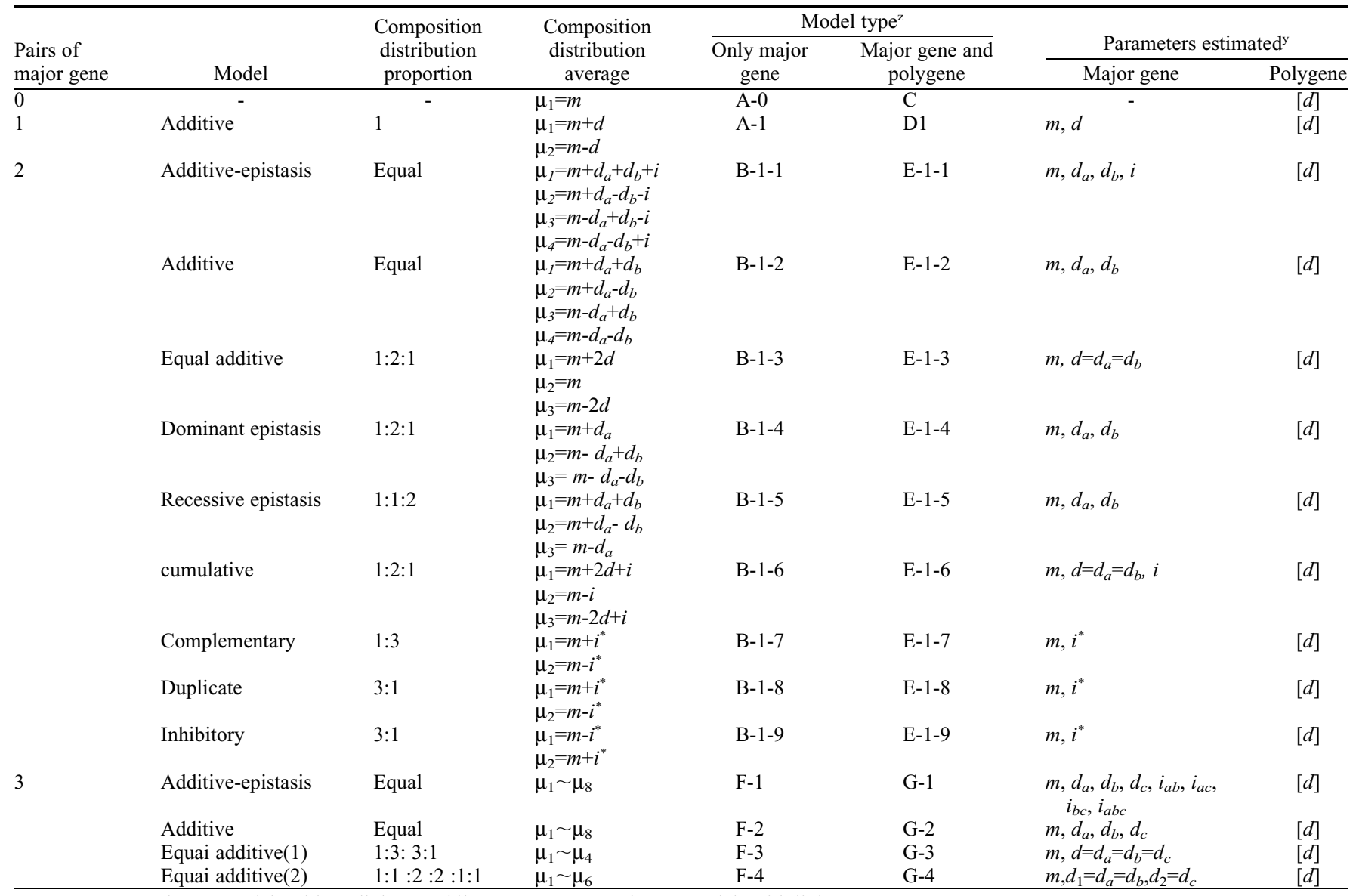

${ }^{\mathrm{z}} \mathrm{B}-1-\mathrm{X}$ or E-1-X denote models without linkage, while B-2-X or E-2-X denote models with linkage.

${ }^{\mathrm{y}} \mathrm{m}$, population mean; $d$, major gene additive effects for models $\mathrm{A}$ and $\mathrm{D} ; d_{a}, d_{b}$, and $d_{c}$, additive effects of the first, second, and third major genes, respectively, for models B, E, F, and $\mathrm{G} ; i$, additive $\times$ additive effect of the two major genes for models B and $\mathrm{E} ; i_{a b}, i_{a c}, i_{b c}$, and $i_{a b c}$, interaction effect of the first and second major genes, the first and third major genes, the second and third major genes, and the three major genes, respectively, for models $\mathrm{F}$ and $\mathrm{G} ; i^{*}$, includes additive and additive $\times$ additive effects. 
Supplemental Table 3. Tests for goodness of fit of alternative models.

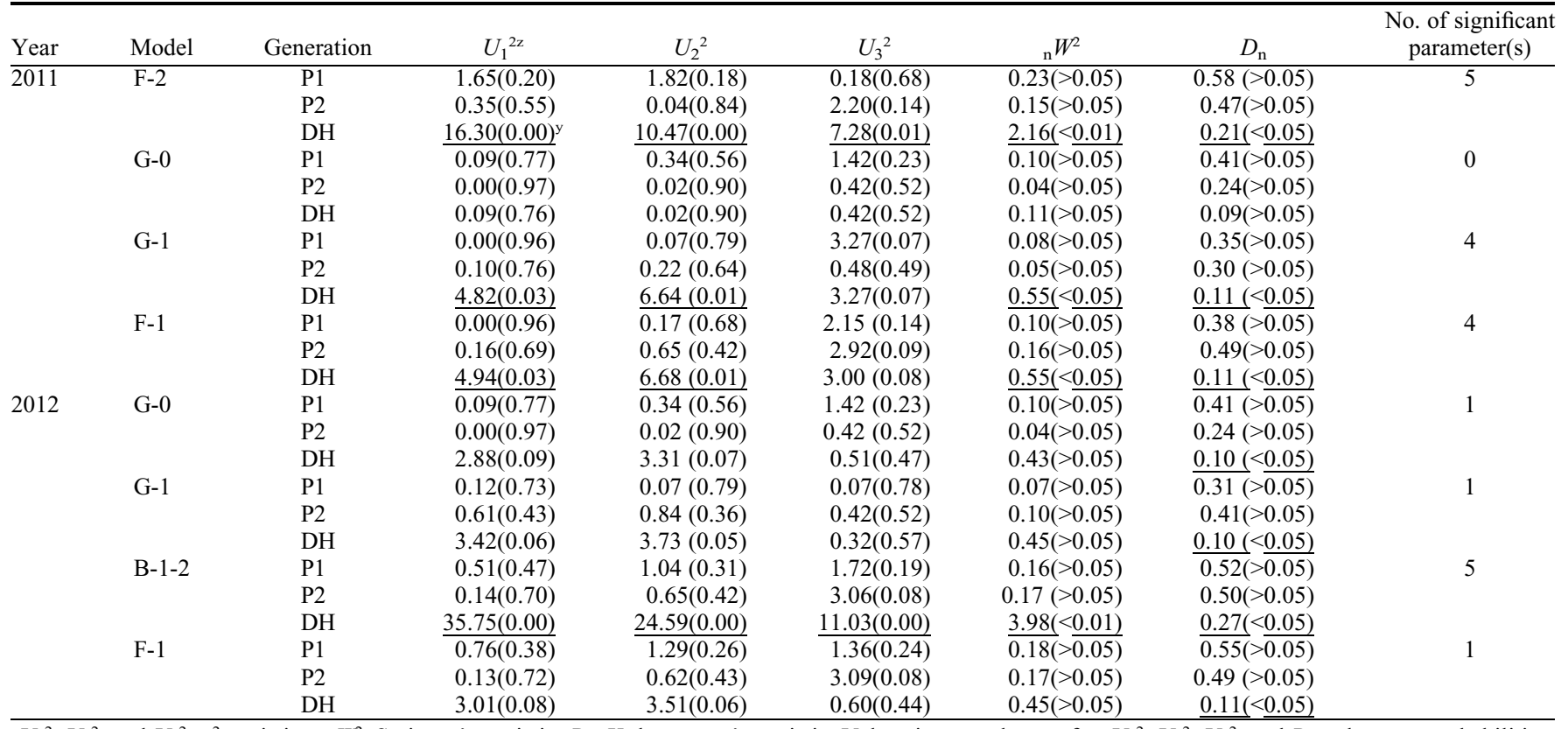

${ }^{\mathrm{z}} U_{1}^{2}, U_{2}^{2}$, and $U_{3}^{2}, \chi^{2}$ statistics; $\mathrm{n} W^{2}$, Smirnov's statistic; $D_{n}$, Kolmogorov's statistic. Values in parentheses after $U_{1}^{2}, U_{2}^{2}, U_{3}^{2}$, and $D_{n}$ values are probabilities; values of $\mathrm{n} W^{2}$ are 0.461 and 0.743 at $P<0.05$ and $P<0.01$ significance levels, respectively.

${ }^{y}$ Underlined values are significant. 